\title{
Research on the Construction and Sharing of High-Quality Resources by Cloud Teaching Materials
}

\author{
Fang Yang ${ }^{1, a, *}$ and Keyue Zhang ${ }^{1, b}$
}

\author{
${ }^{1}$ Hanzhong Vocational and Technical College Intelligent Teaching Resource Center, Shaanxi, China \\ a1770320208@qq.com, ${ }^{b} 119098043 @ q q . c o m$ \\ *Corresponding author
}

\begin{abstract}
In the era of "Internet + " big data, the means of higher vocational education is also undergoing major changes. Hanzhong Vocational and Technical College cooperates with the times to promote the MOOT concept in Shaanxi, and independently develops a teaching management platform based on cloud teaching materials. We lead into the large-scale open online teaching mode (MOOT), which is Proven more suitable for students to immerse deep self-learning, and more suitable for teachers to carry out flip-style classroom (mixed) teaching. Keywords: "Internet + Education", classroom teaching, teaching resources, teaching management, cloud teaching platform
\end{abstract}

\section{基于云教材的优质资源建设与共享实践研究}

$$
\text { 杨方 }{ }^{1, \mathrm{a}, *} \text {, 张可跃 } 1, \mathrm{~b}
$$

\footnotetext{
1 汉中职业技术学院智能教学资源中心, 陕西, 中国

a1770320208@qq.com, ${ }^{b} 119098043 @ q q . c o m$

*通讯作者
}

\section{摘要}

在 “互联网+” 的大数据时代, 高职教育手段也正在发生重大变革。汉中职业技术学院与时俱进校企合 作, 在陕南率先引入 MOOT 理念, 自主开发基于云教材的教学管理平台, 通过广大学生使用后的实践 证明, 我院大范围开放式在线教学模式 (MOOT) 的引入, 更适合学生沉浸式深度自主学习, 也更适 合教师开展翻转式课堂（混合式）教学。

关键字: “互联网+教育”，课堂教学，教学资源，教学管理，云教学平台

\section{1. 教学资源建设与共享的现状}

国外院校的基础教学教材, 通常使用的是信息化、智能化 的慕特教材。慕特(MOOT- Massive Open Online Textbook), 即大范围开放式在线教科书, 是互联网与教学过程的深 度融合。MOOT 是基于课堂教学的互联网智能化教材, 全面支持教师的课堂化教学, 支持学生的自主学习, 和个 性化评价管理体系。

人工智能、移动互联网、云计算和大数据技术为国内教育 教学带来重大变革机遇, 以手机为代表的智能终端正式成 为高校教师开展课堂互动、反馈、激励和评价的必备工具, “以学生为中心” 的新型教学模式开始在国内普及流行。 随着互联网时代的快速发展, 也给广大高职院校的发展带 来了巨大的冲击, 汉中职业技术学院践行 “让教与学由此
不同” 的教育理念, 积极响应时代号召校企合作成立陕南 云墨大数据中心, 构建智能化教学工具、智能化教学资源 和智能化教学管理体系让我院实现从信息化教学到智能 化教学的跨时代飞跃。

\section{2. 云教学平台的构建}

\section{1. 实例研讨}

我们以美国教科书出版商 Pearson(培生集团)提供的 MyMathLab 平台的代数课程为例, 简要分析一下这个平 台提供的慕特教材。这种教材既可以在传统课堂使用, 又可以在互联网在线教育中使用。 


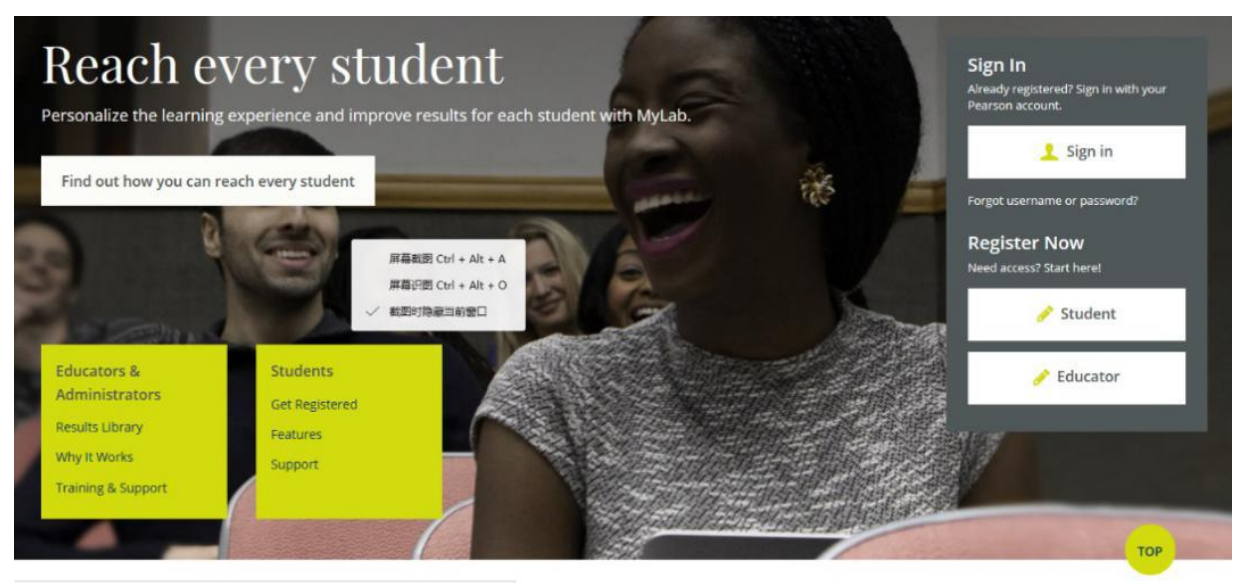

图 1 MyMathLab 平台

MyMathLab 平台具备 14 项功能，包括简介、教师信息、 学生信息、电子教材、互动多媒体资源、视频、家庭作业 和练习、学习助手和即时反馈、自动评判、学习计划、成 绩追踪、学生组织者、教学资源、课外辅导、教师专业发 展。实践证明通过使用这样教材和教学方式, 能使教师和 学生深切感受到教材便捷、便宜、质量高等特点, 从而令
教学效果大为提高。

\subsection{MOOT 开发云教材的特点}

基于互联网的智能化教材, 它与传统的纸质或电子版教材 有着本质的区别。

\begin{tabular}{|c|c|c|}
\hline 特征 & 纸质教材 & 云教材 \\
\hline 版面设计 & 印刷设计，受成本限制 & 天然的数字产品设计, 杂志化风格排版, 版面精致 \\
\hline 多媒体素材 & 黑白小图片 & $\begin{array}{c}\text { 提供丰富的可以放大的高清图片、画廊、视频、音频、动画、 } \\
\text { 3D 等 }\end{array}$ \\
\hline 交互学习 & 暂无 & $\begin{array}{c}\text { 提供趣味化、游戏化、情景化的交互评测、交互练习、交互游 } \\
\text { 戏 }\end{array}$ \\
\hline 扩展学习 & 不方便 & $\begin{array}{c}\text { 提供便捷的扩展学习, 如名词术语、人物事件、知识点气泡标 } \\
\text { 注, 全文任意选择扩展百科和在线字典 }\end{array}$ \\
\hline 学习辅导 & 弱 & $\begin{array}{c}\text { 提供书签、高亮、全文检索、学习记录、笔记分享、发起讨论 } \\
\text { 等功能 }\end{array}$ \\
\hline 教学互动 & 暂无 & $\begin{array}{c}\text { 配合移动教学平台, 老师可查阅学生学习进度、发布课程通知、 } \\
\text { 分享课程资料、开展各种类型的教学互动 }\end{array}$ \\
\hline 学习跟踪 & 暂无 & 查阅学生的学习进度、每章学习时长和笔交互测试结果等 \\
\hline 携带数量 & 有限制 & $\begin{array}{c}\text { 一个智能终端装下所有教材, 随时随地进行学习, 不受操作系 } \\
\text { 统限制 }\end{array}$ \\
\hline 更新迭代 & $\begin{array}{c}\text { 不及时, 通常在每一版售 } \\
\text { 完后 }\end{array}$ & 支持内容及时更新, 特别对交叉学科和知识更新较快的学科 \\
\hline 个性化定制 & 难, 倾向于标准化教材 & 内容个性化定制, 更能适应每个院校的教学需求 \\
\hline
\end{tabular}

表 1 云教材特点

（1）基于互联网, 基于课堂教学, 基于纸质教材, 线上 线下融合。也就是说: 慕特不仅不排斥纸质教材, 而且是
以纸质教材内容为基础来构建的, 这符合中国现有的教材 管理基本模式; 慕特与慕课不同, 慕课是一个不需要课堂 
（1）出版商。云教材是一种 “新教材”, 对出版商而言, 只要有创新的理念和致力于在线教材的魄力,完全可以在 现有的教材管理机制下推动使用。具体的要求, 保持纸质 教材和在线教材并存模式, 将在线功能作为 “教辅” 通过 市场机制推广。

（2）移动跨平台终端及富媒体。在 “三通两平台”模式 下，通过大小屏适配技术、一次制作、一次发布、实现跨 平台使用全面支持 iPhoneliPad $\backslash$ Android 手机、平板、 $\mathrm{PC}$ 设备。在多场景中选用混合媒体一体化编排设计，文字、 图片、画廊、语音、视频、3D 等技术，实现学、练、测 的交互沉浸式学习。

（3）教学资源与专家团队。丰富和动态调整现有教学资 源是实现云教材的关键，一是利用或收购优质教育资源 (比如通过免费资源平台); 二是组建一个高水平的和相对 稳定的专家团队, 从事资源的不断丰富和审核, 确保其优 质与实用; 三是建立开放的激励机制, 通过人人参与和人 人贡献实现资源的丰富和更新。

\section{4. 云教材的开发}

基于云教材的优质教学资源共享的主要研究目标是创建 一整套适合汉中职业技术学院智能教学资源整合发展的 平台, 和可以多元化共享的数据资源。在 WIN 10 平台上, 采用 PHOTOSHOP、HTML5、CSS、JAVASCIRIPT、在 线编辑器等开发工具, 我院自主对现有一流专业教学资源 进行二次在线开发, 主要包括 MOOT 混合媒体、场景交 互学习、碎片化学习和体系化学习场景自主融合切换、呈 现共性学习内容, 并充分展示教师个性等方面的内容。

大量丰富的教学资源是云教材开发的基础和保障, 交互灵 活的云教材又让教学资源的 “共享化服务” 成为现实。 


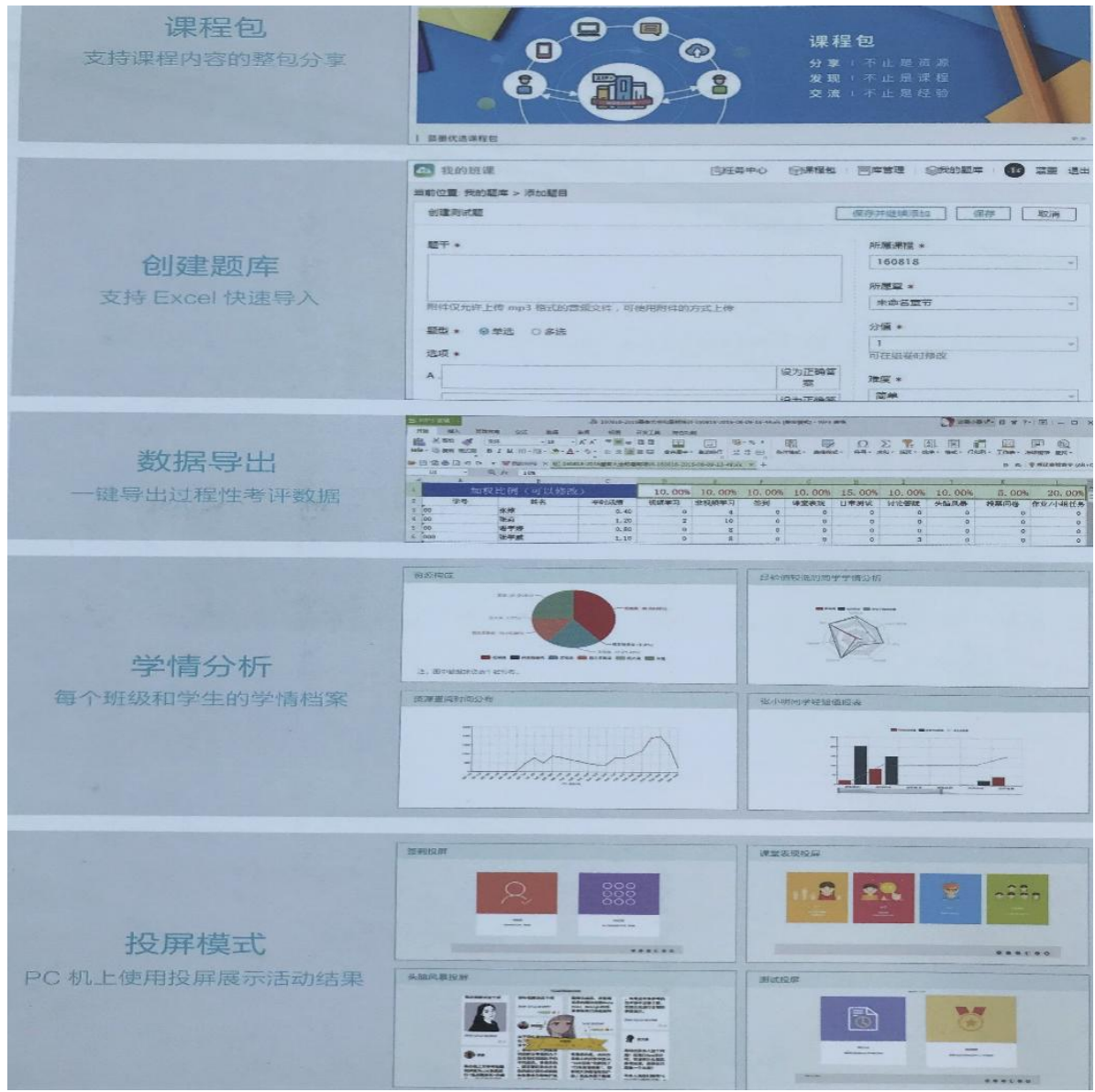

图 2 云教材系统

\section{5. 云教学平台的实践}

目前我院选择北京智启蓝墨信息技术有限公司提供的大 数据平台, 自主开发创建云教材及教学管理体系, 使互联
网技术与教育教学能够深度融合, 从而推动陕南区域高职 院校共享在线开放式教学资源的广泛应用。

(1)云教学为每一名教师和学生提供一个交互管理空间, 它是建立在每一门课程学习的基础之上, 从而使云教材进 入教与学的核心环节之中。 


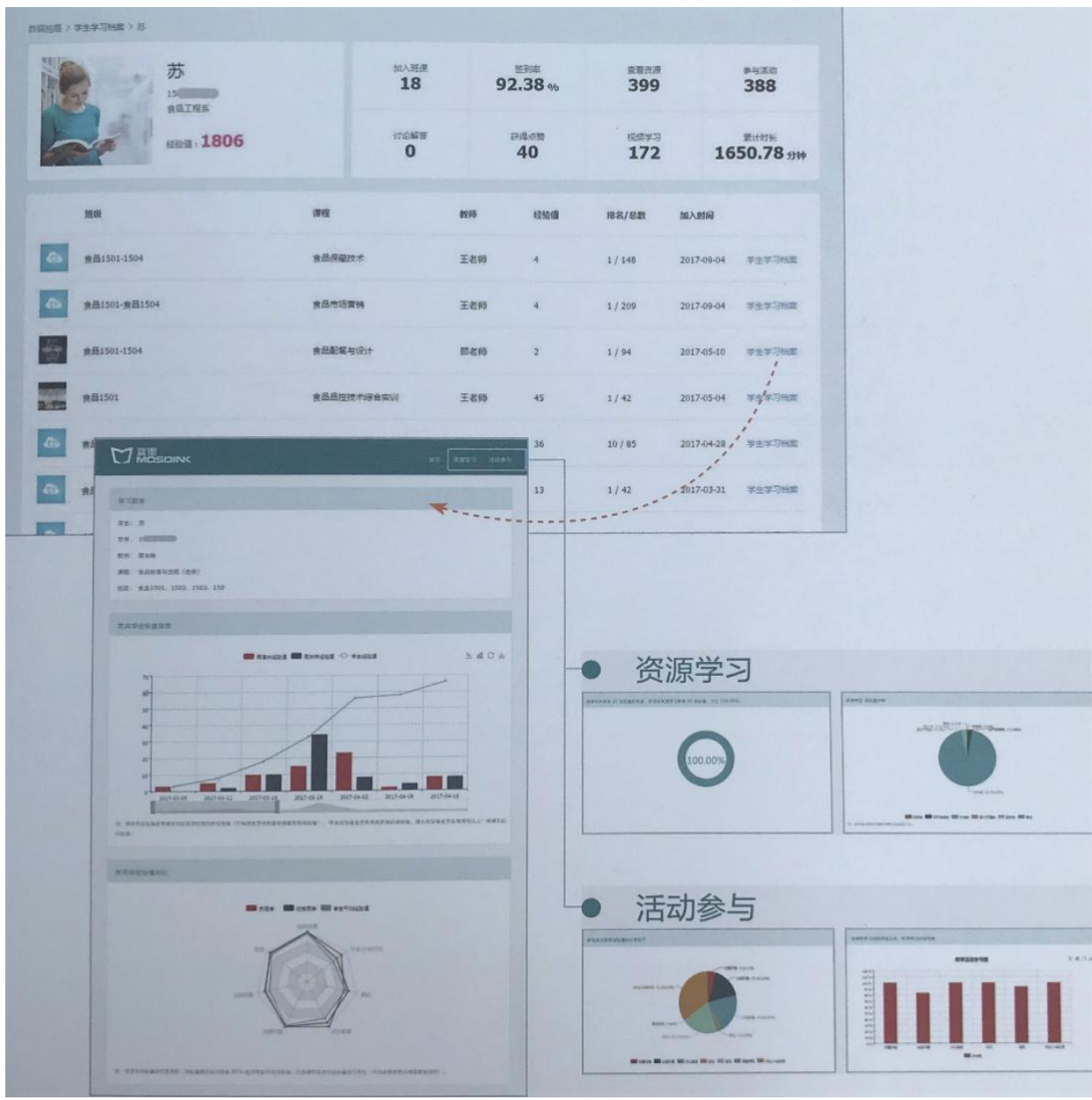

图 3 学生学习档案

（2）云教材与资源平台。云教材需要大量丰富的教学资 源, 它所汇聚的教学资源是围绕课程和教材内容的, 为教 师和学生提供有针对性的支持, 同时每一名教师和学生也 是教学资源的创造者。所以, 优质教学资源共享将为每一 个 MOOT 提供有力支持, 并使其价值通过开放性充分 的发挥出来。
（3）教学资源与管理平台。在云教材共享时, 不同地域 不同院校的学生和教师同时使用时, 教学评价和管理功能 中学生和教师的身份认证数据管理就体现的尤为重要。管 理平台所产生的大量数据为以后大数据分析挖掘提供大 量极具价值的成果。 


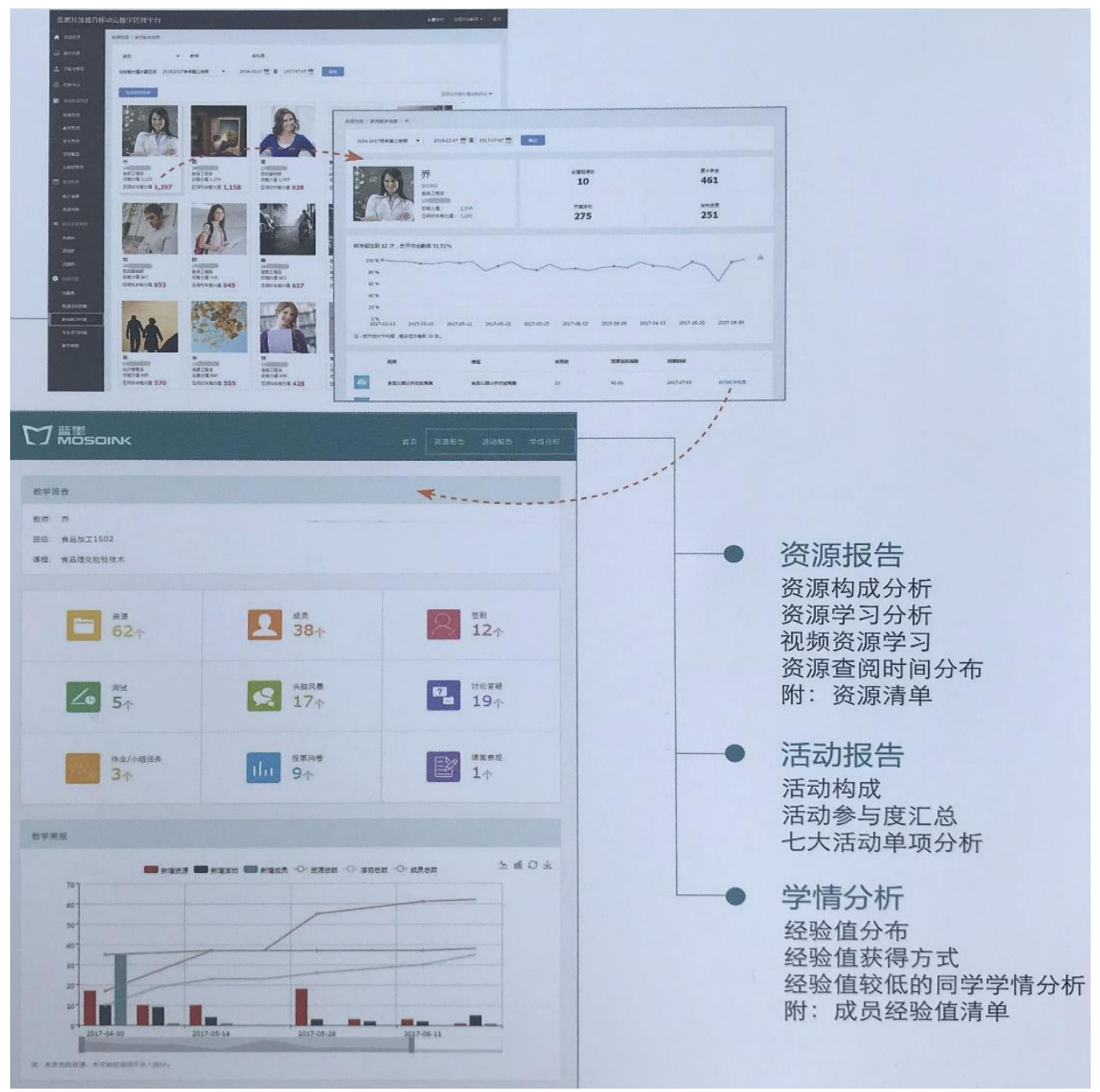

图 4 教师教学管理档案

\section{3. 结束语}

“互联网+” 能够为教育带来新的 “革命性影响”, MOOT 对教材、教学过程、教学评价乃至出版业的影响将是深远 的。本研究基于云教材平台, 自主研发适用于学院多学科 的特色云教材。通过移动智能终端设备, 融合微课、动画、 音视频、3D 等多媒体资源, 建立学习互助、交互测试、 笔记社交、知识点讨论模式让学生自主学习, 让笔记、百 科、朗读、字典等辅助支持功能和学习场景完美的融合起 来, 在探索新型教育服务供给方式给出新的思路, 使 “互 联网+教育”优质资源建设与共享成为现实。

\section{致谢}

本文为陕西省职业技术教育学会基金项目《“互联网+教 育” 优质资源建设与共享研究》(编号: SZJYB19-054)的 阶段性成果之一。

\section{参考文献}

[1] The significant influence of emerging information technology in the 21 st century on education deepening reform [J]. Keai He. China Modern Educational Equipment. 2018 (16).

[2] Application of Big Data Mining in Personalized Teaching of Internet Education Platform[J]. Shufang Yang, Chen Huang, Guozhong Gong, Zhengjun Jing. China Management Informationization. 2018(19).

[3] The Dilemma and Coping Strategies in the Digital Transformation of Education Publishing $[\mathrm{J}]$. Bin Li. Media Forum. 2018(19).

[4] Opportunities and Challenges of China's Open University in the Age of "Internet +"[J]. Li Chen, Qinhua Zheng, Shiren Lin. Open Education Research. 2017(01).

[5] The Construction of Teacher Education Curriculum Resources under the Background of "Internet +"[J]. Deying Yu. Educational Theory and Practice. 2016(23).

[6] Analysis of the Concept and Model of "Internet + Education" [J]. Yan Zhang. China Higher Education Research. 2016(02).

[7] Opportunities and Challenges of Distance Education in China in the Age of "Internet +"[J]. Li Chen, Shiyuan Lin, Qinhua Zheng. Modern Distance Education Research. 2016(01). 
[8] Knowledge Management Process in Multi-Site Provision of Service[J] . Rodrigo Valio Dominguez Gonzalez. International Journal of Knowledge Management (IJ . 2016 (2).

[9] Information Resource Management [M]. Higher Education Press, Feicheng Ma, 2014. 